\title{
Investigating the Effects of Different Geometries Used In Flexural Hinges on Their Fatigue Life
}

\author{
Milind Sawant ${ }^{1}$, Prashant Anerao ${ }^{2}$ \\ ${ }^{1}$ PG Student, Vishwakarma Institute of Information Technology, Kondhawa (Bk), Pune-411048, India \\ ${ }^{2}$ Assistant Professor, Mechanical. Department, Vishwakarma Institute of Information Technology, Kondhawa (Bk), Pune-411048, India
}

\begin{abstract}
A rigid link mechanism can be converted into a compliant mechanism by replacing rigid joints with flexural hinges. In most of the compliant mechanism, it is found that the compliant mechanism fails at flexural hinges due to cyclic load. To minimize the failure i.e. increasing the fatigue life of these flexural hinges, different configurations of geometries have been tried. This paper presents a methodology for calculating the fatigue life of flexural hinges by using analytical approach. This paper also discusses different geometries available for design of flexural hinges like circular, rectangular and parabolic along with the effect of geometry on the fatigue life cycle of the flexure hinge. The design flexural hinge is done for compliant mechanisms used for displacement amplification applications. Finite element analysis has been carried out to validate the fatigue life calculated by analytical approach and results are discussed in this paper.
\end{abstract}

Keywords: compliant mechanisms, circular hinge, elliptical hinge, flexure hinges, rectangular hinge

\section{Introduction}

The design of micro mechanisms, compliant mechanisms have becomes a quite popular in recent years because of their wide applications. Such mechanisms becomes more and more common in various fields of applications, examples are medical engineering, measurement instrumentations, precision engineering and microsystem technology. This is due to the many advantages of complaint mechanisms such as no friction, consequently little to no wear and no necessity for maintenance, the potential for miniaturization and its monolithic construction. ([1],[2],) Complaint mechanisms achieve their motion with the elastic deformation of flexural hinges which are replacement of traditional rigid joints. Such monolithic and inherently flexible complaint mechanisms consist of solid elements coupled by elastic hinges. The functional performance which means path of motion of these mechanisms was depends on its complaint joints. They generate smooth and continuous displacement without backlash. With a suitable choice of material, flexure joints exhibit predictable and repeatable relationship between force and displacement. For monolithic compliant mechanisms and flexure hinges, these characteristics only depend on the geometry which is characterized by the notch contour.([3],[4],[5],[6],[7]) Approaches for notch contours, based on geometric primitives. The different primitives are shown below.

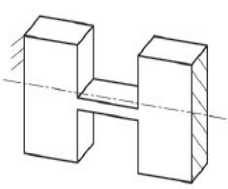

(I)

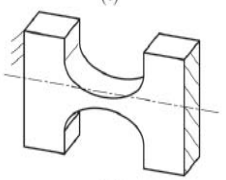

(IV)

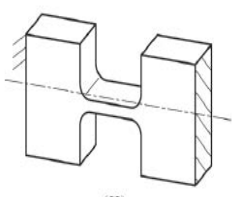

(II)

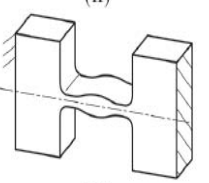

(V)

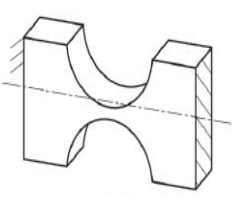

(III)

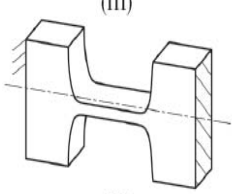

(VI)
(III) Circular contour, (IV) elliptical contour, (V) spline contour and (VI) polynomial contour.

\section{Analysis of Hinges}

The influence of the hinge geometry on the deformation behavior of such flexure hinges has been investigated in several former contributions (e.g. [8], [9]). These types of hinges effect on performance of path of mechanism. In literature it is found that the flexural hinges were fails under the cyclic load, at flexural shape of hinge. Many researcher works on fatigue life of complaint mechanism, according to them determination of fatigue life flexural hinge is one of most important parameter to determine the life cycles of complaint mechanisms.([10],[11])

In this work, effect of different geometry on the fatigue life of hinge is analyzed with the help of finite element analysis. According to most widely used applications, rectangular, circular and parabolic shaped geometry hinges are chosen. And analyses it by providing constant ratio of hinge height to neck height, also the notch sensitivity, surface finish factor, size factor also took in account, Flexure joint may also be sensitive to temperature variation as a result of thermal expansion and contraction, so factor of thermal expansion is very important in analysis process.

Dimensions and force parameters.

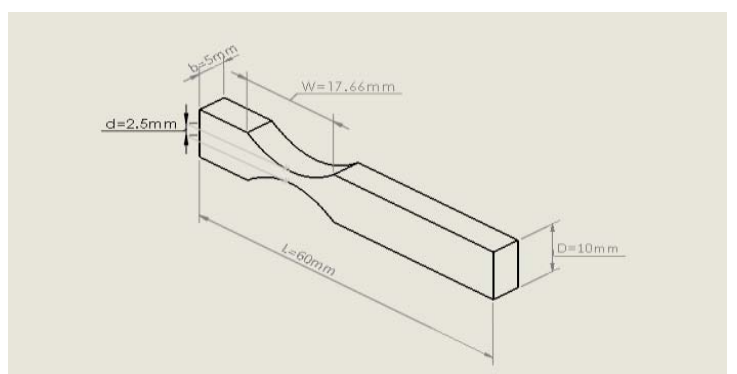

(1)

Figure1: Types of prismatic flexure hinges - (I) rectangular contour, (II) corner filleted contour, 


\section{International Journal of Science and Research (IJSR)}

ISSN (Online): 2319-7064

Index Copernicus Value (2013): 6.14 | Impact Factor (2014): 5.611

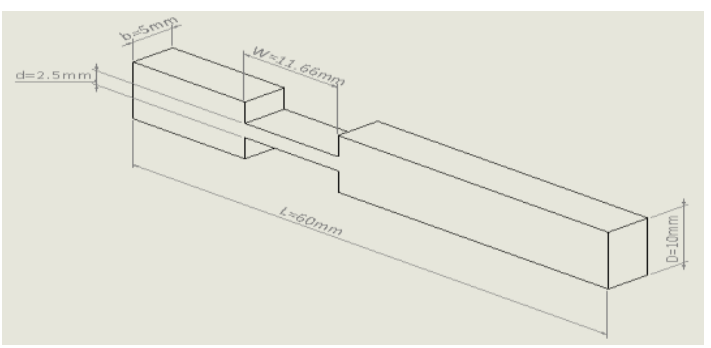

(2)

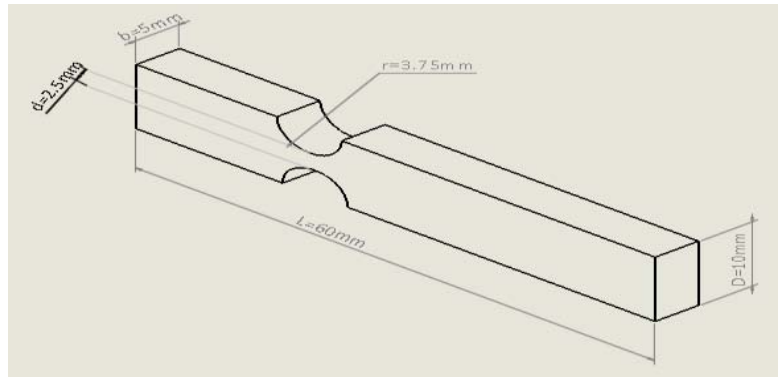

(3)

Figure 2: dimensions of (1) parabolic (2) rectangular and (3) circular hinges respectively

In this analysis location of notch is $2 / 3$ of length $L$ from force is activated at end of length as like cantilever beam, other parameters of hinge are height $d$, neck height $d$, and particularly we focused on maintaining the ratio of $\mathrm{D} / \mathrm{d}$ is same or constant for all type of flexural hinges. Basically this ratio is describing the stiffness strength of that hinges. Their failure was occurs in the notched area of flexural hinges, notch sensitivity factor is important in design of flexural hinges.

Following calculations conducting for Ultimate stress for AISI 304 is $860 \mathrm{mpa}$ and other properties are

Table 1: Material Properties of AISI304

\begin{tabular}{|c|c|c|c|}
\hline & Property & Value & Unit \\
\hline 1 & Density & 7850 & $\mathrm{Kg} / \mathrm{m}^{\wedge} 3$ \\
\hline 2 & Coefficient of thermal expansion & $1.2 \mathrm{E}+5$ & $\mathrm{C}^{\wedge}-1$ \\
\hline 3 & Reference temperature & 22 & $\mathrm{C}$ \\
\hline 4 & Young's modulus & $2 \mathrm{E}+5$ & $\mathrm{Mpa}$ \\
\hline 5 & Passion's ratio & 0.3 & \\
\hline 6 & Tensile yield strength & 690 & $\mathrm{Mpa}$ \\
\hline 7 & Compressive yield strength & 690 & $\mathrm{Mpa}$ \\
\hline 8 & Tensile ultimate strength & 860 & $\mathrm{Mpa}$ \\
\hline
\end{tabular}

\section{Endurance Limits Approximate Estimation}

There are two separate notations used for endurance limit $S^{\prime}{ }_{e}$ and $S_{e}$ where $S^{\prime}{ }_{e}$ is endurance limit stress of a rotating beam specimen subjected to reversed bending stress. $\mathrm{S}_{e}$ is endurance limit stress of particular mechanical component specimen subjected to reversed bending stress.

There is approximation relationship between the endurance limit and ultimate tensile strength $\left(\mathrm{S}_{\mathrm{ut}}\right)$ of material. For steel it is $\mathrm{S}_{\mathrm{e}}^{\prime}=0.5\left(\mathrm{~S}_{\mathrm{ut}}\right)$

Relationship between $S_{e}$ and $S^{\prime}{ }_{e}$ by shigly ([12]) is as follows

$$
\mathrm{S}_{\mathrm{e}}=\mathrm{K}_{\mathrm{a}} \times \mathrm{K}_{\mathrm{b}} \times \mathrm{K}_{\mathrm{d}} \times \mathrm{S}_{\mathrm{e}}^{\prime}
$$

\section{Stress Concentration Factor}

The stress concentration factors are determinate by two methods, first is the mathematical method based on the theory of elasticity and another is experimental methods like photo elasticity. The charts for stress concentrations factors for different geometric shapes and conditions of loading were originally developed by RE Peterson.[13]

Stress concentration factor $\mathrm{K}_{\mathrm{t}}=1.4$

For $\frac{\mathrm{D}}{\mathrm{d}}=\frac{10}{2.5}=4 ; \frac{\mathrm{r}}{\mathrm{d}}=\frac{3.75}{2.5}=1.5$

\section{Notch Sensitivity Factor $q$}

Notch sensitivity is defined as the susceptibility of a material to succumb to damaging effect of stress raising notches in fatigue loading. The notch sensitivity $\mathrm{q}$ is defined as

$$
q=\frac{\text { Increase of actual stress over nominal stress }}{\text { Increase of therotical stress over nominal stress }}
$$

Generally the magnitude of notch sensitivity factor q varies from 0 to 1 . The Notch sensitivity factors different for various materials and stress conditions like for reversed bending and for reversed torsional shear stress.

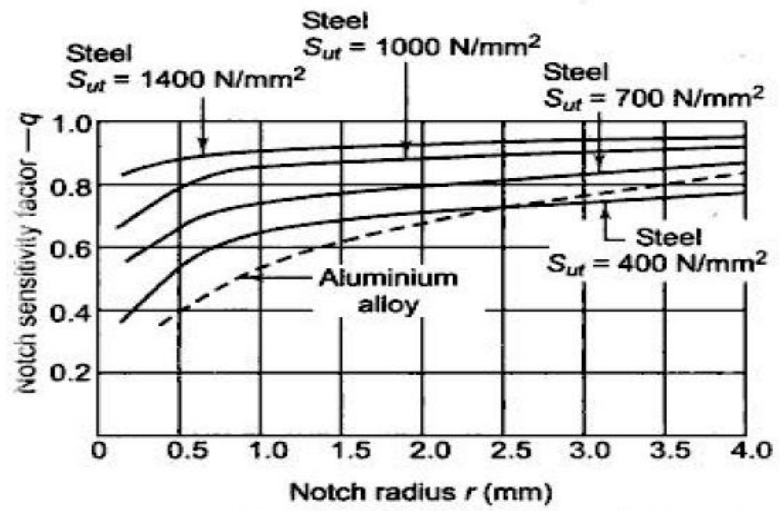

Figure 3: Notch sensitivity charts (for reversed bending and reversed axial stresses) ([14])

\section{Modifying Factor to Account for Stress Concentration Factor $\mathbf{K}_{d}$}

The endurance limit is reduces due to stress concentration. The stress concentration factor is used for cyclic loading is less than the theoretical stress concentration factor due to notch sensitivity of the material. To apply the stress concentration effect, we can either reduce the endurance limit be $\mathrm{K}_{\mathrm{d}}$ or increase the stress amplitude by $\mathrm{K}_{\mathrm{f}}$. We will use first approach. 


\section{International Journal of Science and Research (IJSR) \\ ISSN (Online): 2319-7064}

Index Copernicus Value (2013): 6.14 | Impact Factor (2014): 5.611

Fatigue stress concentration factor $\mathrm{K}_{\mathrm{f}}$

$\mathrm{K}_{\mathrm{f}}=\frac{\text { Endurance limit of notch free speciman }}{\text { Endurance limit of notched speciman }}$

Modifying factor to account for stress concentration factor $\mathrm{K}_{\mathrm{d}}$

$\mathrm{K}_{\mathrm{d}}=\frac{1}{\mathrm{~K}_{\mathrm{f}}}$

\section{Size factor $\mathbf{K}_{\mathrm{b}}$}

Shigley and Mischke ([12]) have suggested an exponential equation for size factor $\mathrm{K}_{\mathrm{b}}$ for bending and torsion the equation is in following form

For $2.79 \mathrm{~mm}<\mathrm{d}<51 \mathrm{~mm}$

$\mathrm{K}_{\mathrm{b}}=1.24 \mathrm{~d}^{-0.107}$

For $51 \mathrm{~mm}<\mathrm{d}<254 \mathrm{~mm}$

$\mathrm{K}_{\mathrm{b}}=0.895-0.000873 \mathrm{~d}$

\section{Nominal stress or safe stress is}

$\sigma_{0}=\frac{\mathrm{M}}{\mathrm{I}} \times \mathrm{y}$

Where $I=\frac{b d^{8}}{12}$

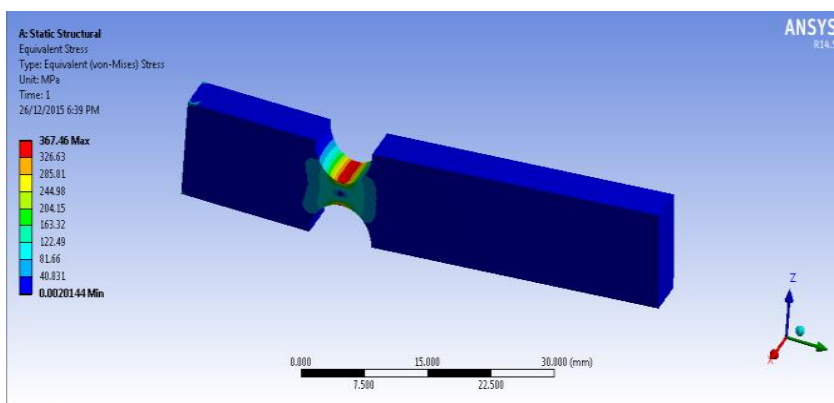

Figure 4: Equivalent von mises stress analyzed by FE model

\section{Fatigue Life Cycles}

When the component is to be designed for finite life, the S-N curve as shown in figure can be used.

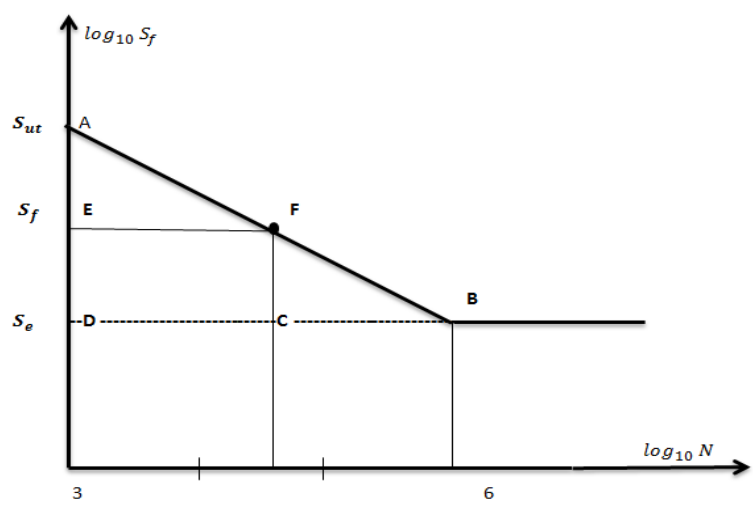

By using the S-N curve

$\overline{\mathrm{EF}}=\frac{\overline{\mathrm{DB}} \times \overline{\mathrm{AE}}}{\overline{\mathrm{AD}}}$

$\log _{10} N=3+\overline{E F}$

By Numerically 3875 cycles can be achieved for circular flexural hinge, after the completion cycles the component fails at flexural or notched shape as shown in figure.

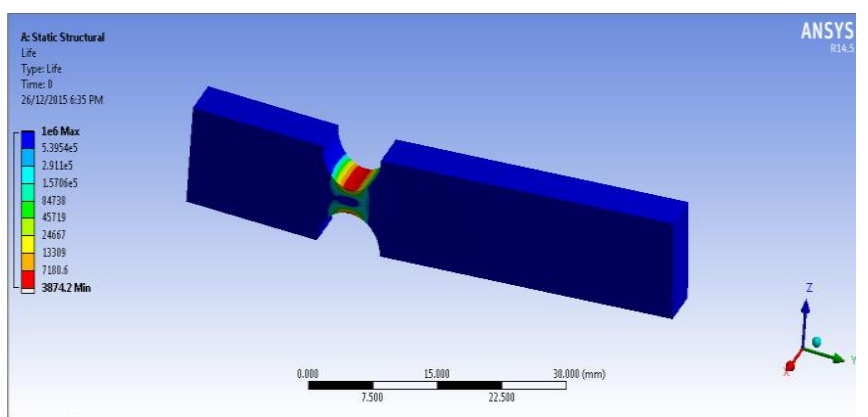

Figure 5: Determination of Fatigue life cycles by FE model

\section{Factor of Safety}

Factor of safety is a term describing the structural capacity of a system beyond the expected loads or actual loads. Essentially, the factor of safety is how much stronger the system is than it usually needs to be for an intended load. Safety factors are often calculated using detailed analysis because comprehensive testing is impractical on many projects.

Factor of sefty $=\frac{\text { Material Stren jth }}{\text { Design load }}$

$\mathrm{f}_{\mathrm{s}}=\frac{\mathrm{S}_{\mathrm{e}}}{\sigma_{0}}$

As known it is term describing the structural capacity beyond its actual load. In our case factor of safety is 0.23 . As increase in factor of safety it tremendously increase in fatigue life cycles.

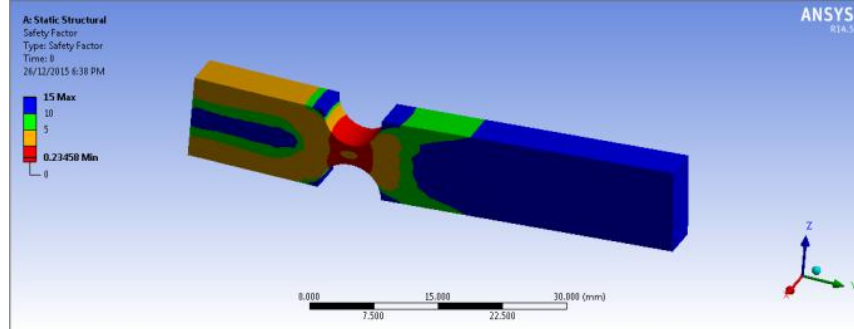

Figure 6: Factor of Safety analyzed by FE model

\section{Yield Strength}

Yield strength is the material property defined as the stress at which a material begins to deform plastically. Prior to the yield point the material will deform elastically and will return to its original shape when the applied stress is removed. Once the yield point is passed, some fraction of the deformation 


\section{International Journal of Science and Research (IJSR) \\ ISSN (Online): 2319-7064}

Index Copernicus Value (2013): 6.14 | Impact Factor (2014): 5.611

will be permanent and non-reversible. The stress at which yield occurs is dependent on both the rate of deformation (strain rate) and, more significantly, the temperature at which the deformation occurs. Generally, the yield strength increases with strain rate and decreases with temperature rate.

$\mathrm{S}_{\mathrm{yt}}=\frac{\mathrm{f}_{\mathrm{s}}}{\sigma_{\max }}$

Similarly, design of rectangular flexural hinge as well as parabolic hinges is carried out, center of location and its D/d ratio is maintaining constant for all design calculations. The results are given below:
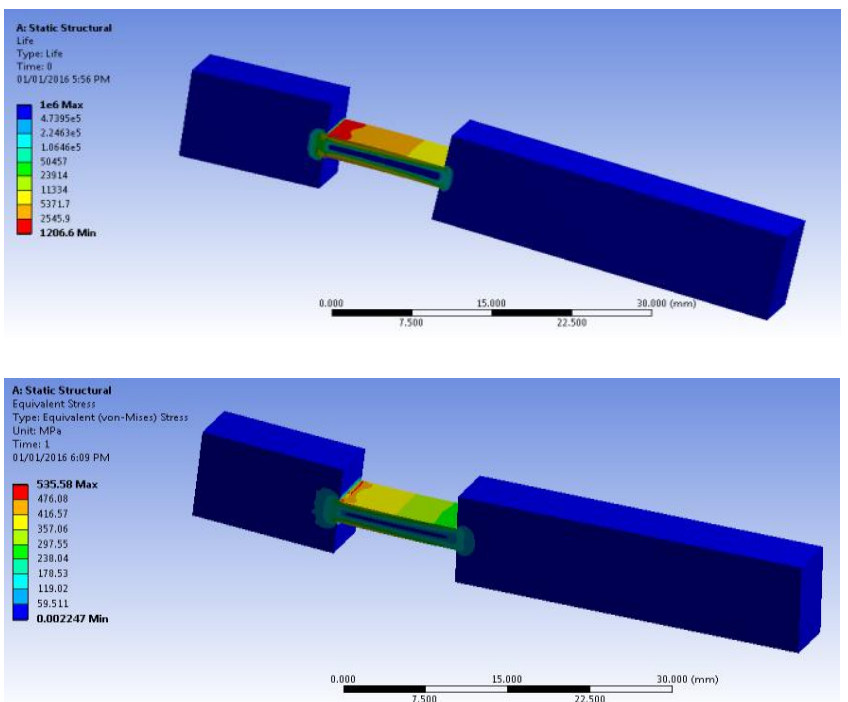

Figure 7: FE model of rectangular flexural hinge for fatigue life and maximum stress

In rectangular hinge analysis it should be found that the designed fatigue life cycles are low as compares to other types of flexural hinges.
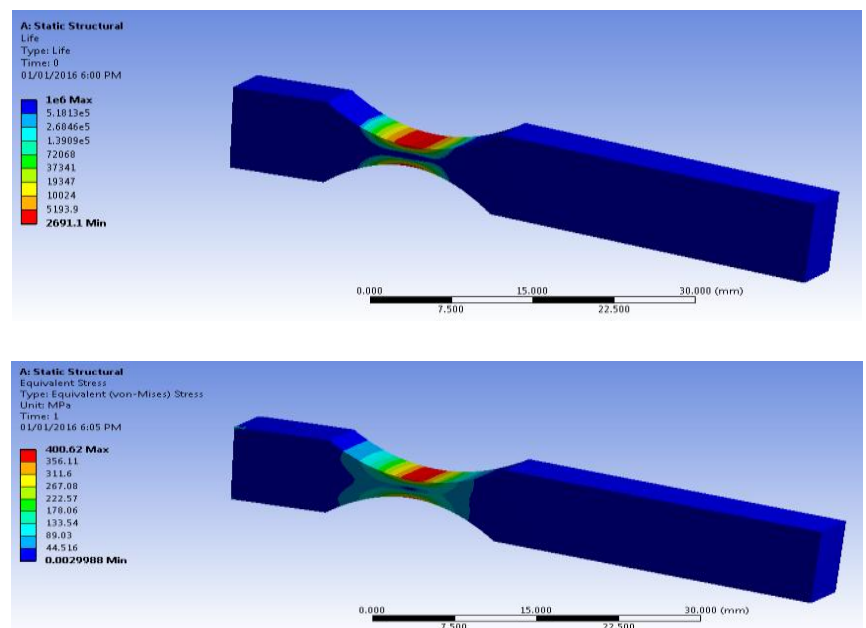

Figure 8: FE model of parabolic flexural hinge for fatigue life and maximum stress

Similarly in parabolic flexural hinge, fatigue life cycles and induced maximum stress is near about same as compare with the circular flexural hinge. Hence it is widely used in micro robotics.

\section{Result and Discussion}

Circular, rectangle, and parabolic flexural hinges are designed by considering different parameters with some constant values then it should be seen according to results the circular flexural hinge is most powerful geometry shape based on fatigue life cycles. The moment of inertia and stress concentration factor is plays important role for deciding the safety factors, no of cycles of different geometrical shape of flexural hinges. Moment of inertia is constant across the flexural shape but in circular and parabolic shaped flexural hinges it changes according to the shapes. The different results are summarized below,

Table 2: Result of different hinges

\begin{tabular}{|c|c|c|c|c|}
\hline Sr. No & Type of hinge & $\begin{array}{c}\text { Max. } \\
\text { stress in } \\
\text { mpa }\end{array}$ & $\begin{array}{c}\text { Fatigue life } \\
\text { in cycles }\end{array}$ & $\begin{array}{c}\text { Factor of } \\
\text { safety }\end{array}$ \\
\hline 1 & $\begin{array}{c}\text { Circular flexural } \\
\text { hinge. }\end{array}$ & 382.67 & 3100.8 & 0.22 \\
\hline 2 & $\begin{array}{c}\text { Parabolic } \\
\text { flexural hinge. }\end{array}$ & 400.62 & 2691.1 & 0.21 \\
\hline 3 & $\begin{array}{c}\text { Rectangular } \\
\text { flexural hinge. }\end{array}$ & 535.58 & 1206 & 0.16 \\
\hline
\end{tabular}

Reducing the force or increasing the neck thickness of hinge gives the increasing life cycles and better factor safety which will more than 1 .

\section{Conclusion}

In order to avoid failure of complaint mechanism before its signified life, explicit method for obtained the fatigue life of circular, parabolic and rectangular flexural hinge. From these results it should be found that circular flexural hinge having max. Stress and life cycles, hence it is greatly suitable for development of pantograph mechanism. It describes key parameters that affect the performance of different shape of flexural hinge, which can provide directions of design precision for the flexible hinge.

\section{Reference}

[1] Howell, L. L., "Compliant mechanisms," New York: Wiley, 2001.

[2] S. Linß, A. Milojević, L. Zentner "Considering the Design of the Flexure Hinge Contour for the Synthesis of Compliant Linkage Mechanisms" Technische Universität 58th Ilmenau Scientific Colloquium September (2014) PP. 1-12

[3] R. Ryan Vallance, Behnoush Haghighian , Eric R. Marsh "A unified geometric model for designing elastic pivots" Precision Engineering vol 32 (2008) pp. 278288

[4] F. Dirksen, M. Anselmanna, T. Zohdi, R. Lammering "Incorporation of flexural hinge fatigue-life cycle criteria into the topological design of compliant small-scale devices" Precision Engineering (2013) pp. 1-11

[5] S. Linß, T. Erbe, L. Zentner "On polynomial flexure hinges for increased deflection and an approach for simplified manufacturing" 13th World Congress in 
Mechanism and Machine Science, Guanajuato, México, June, (2011) pp. 1-9

[6] F. Dirksen and R. Lammering "On mechanical properties of planar flexure hinges of compliant mechanisms" Copernicus Publications Mechanical. Science. Vol. 2 (2011) pp.109-117.

[7] Y. Tian, B. Shirinzadeh, D. Zhang, and Y. Zhong, Y. "Three flexure hinges for compliant mechanism designs based on dimensionless graph analysis". Precision Engineering, vol. 34, (2010) pp. 92-100.

[8] N. Lobontiu, Jeffrey S. N. Paine, E. Garcia, M. Goldfarb "Corner-filleted flexure hinges" Journal of mechanical design. Vol. 123 (2001) pp. 346-352

[9] Yuen Kuan Yong, T. Fu Lu, C. Daniel. and Handley "Review of circular flexure hinge design equations and derivation of empirical formulations" Precision Engineering, vol 32 (2008) pp. 63-70

[10] S. Shuib, M.I.Z. Ridzwan and A. H. Kadarman "Methodology of compliant mechanisms and its current developments in applications: A Review" American Journal of Applied Sciences. vol 4 (3) (2007) pp.159-166

[11]N. Lobontiu, Jeffrey S. N. Paine "Design of circular cross-section corner-filleted flexure hinges for threedimensional compliant mechanisms" Journal of mechanical design by ASME Vol. 124 (2002) pp. 479484

[12] Joesph E Shigly "Mechanical Engineering Design" McGraw hill kogakusha, 2004.

[13]R. E. Peterson, "Design Factors for Stress Concentration," Machine Design, vol. 23 no. 7, July (1951) pp. 155

[14] Ralph Stephens, Ali Fatemi, Robert R. Stephens, Henry O.Fuchs "Metal fatigue in engineering" by john wiley \& sons, inc. Article no.7 pp. 196.

\section{Author Profile}

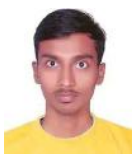

Milind Sawant received the B.E degrees in Mechanical Engineering from K. T. Patil college of engineering and Technology, from Aurangabad university in 2014. He is pursuing M.E. from Pune

University.

Prashant Anerao received the M.Tech degrees in Mechanical Engineering from IIT Mumbai in 2009 